\title{
Edith Roy
}

\section{La Carcajada de la Muerte}

No mucho me gusta salir los fines de semana con mis padres a reuniones familiares ya que me la paso muy ocupada durante la semana y lo único que quiero hacer es relajarme. Pero cuando miro que mi madre empieza a decir que cuando ella muera me recordaré de los momentos que no compartí con ella, me dan ganas de salir corriendo. Papá me mira y me da doscientos quetzales a espaldas de mi madre y me dice "ya te ganaste tu ración semanal." Así que muchas veces decido ir a tales reuniones por mi padre quien le ha tocado pacientemente lidiar con mi madre sin una ración semanal por treinta años de matrimonio.

Exactamente este fin de semana, mi madre me da el mismo discurso. Esta vez, nos fuimos al pueblo donde mis padres crecieron, en Sumpango, Sacatepéquez, a celebrar el día de todos los santos. La única razón por la que me gusta ir al pueblo es porque puedo respirar aire puro, el cual no se respira en la ciudad de Guatemala. Lo demás me lo aguanto ya que mis padres son muy felices al estar con sus familiares.

Ese mismo día que llegamos, decidí ayudar a la abuela con la cena. Estaba yo cortando la cebolla para los frijoles cuando de repente, la abuela al ver mi anillo de compromiso me contó la historia de un duende que trata de enamorar a las jóvenes comprometidas para volverlas en sus novias y llevárselas para siempre. Siendo tan escéptica como lo soy, no le creí a la abuela ya que son cuentos de pueblo. Después de la cena, salí al patio a ver si me podía comunicar con Pablo porque lo extrañaba mucho y estando a una semana de nuestra boda yo sentía que pasar una noche más sin él me iba a matar. De repente, todo se quedo en silencio. La noche se quedo sin estrellas y un viento frío pasó dejándome la piel eriza. No le hice caso pero de repente vi que unos ojos brillantes me estaban viendo desde un arbusto y pensando que era el perro de la abuela me fui a averiguar. Para mi sorpresa, un hombrecillo con una carcajada de niño saltó encima de mí tratando de amarrar mis manos y pies para que yo no escapara. Sorprendentemente, este hombrecillo era muy fuerte y se miraba que no vivía entre los vivos. Quería gritar pero mis gritos no salían de mi boca. Finalmente me logre escapar, pero el hombrecillo me siguió hasta que llegué a la luz y desapareció llevándose un pedazo de mi cabello.

Al entrar a la casa, le conté a mi abuela y me vio como si ella hubiera visto al mismo diablo. Me dijo con mucho miedo que tendría que cuidar de Pablo, ya que el hombrecillo no descansaría hasta quedarse conmigo o separarme de mi amado. En ese momento corrí hacia mi cuarto y agarré mi teléfono y llamé a Pablo. Pablo contestó y mi corazón dejo de palpitar rápido. De repente la llamada se cortó y lo único que oí fue la carcajada de niño de aquel hombrecillo que se llevo a mi prometido para nunca jamás volverlo a ver. 
$t i<1.1$ (Spring 2012)

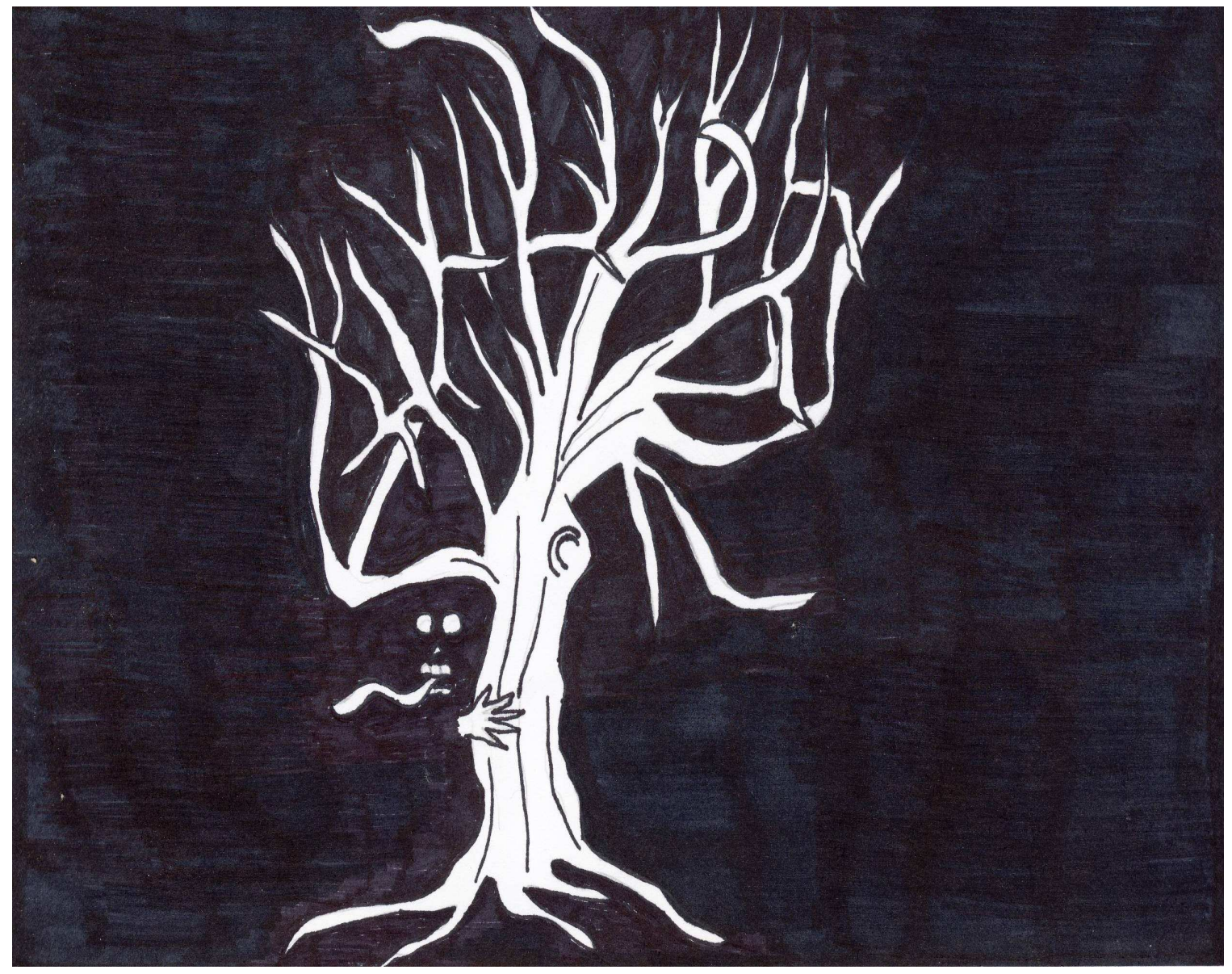


Ethan Tufford

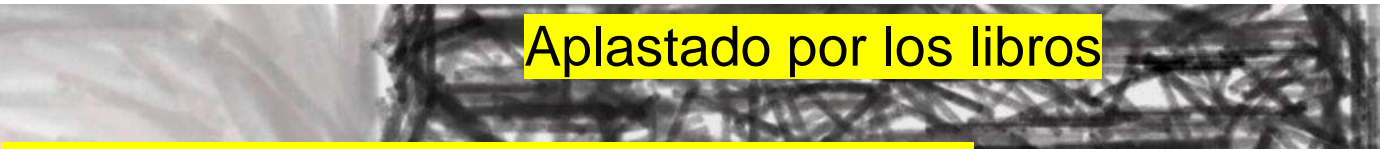

Cientos de miles de libros hay que leer.

Sin completar mi cuota justa, dejo.

¿Puedo y

(x)

o crecer mi conocimiento?

« Es sagrada la búsqueda del saber. »

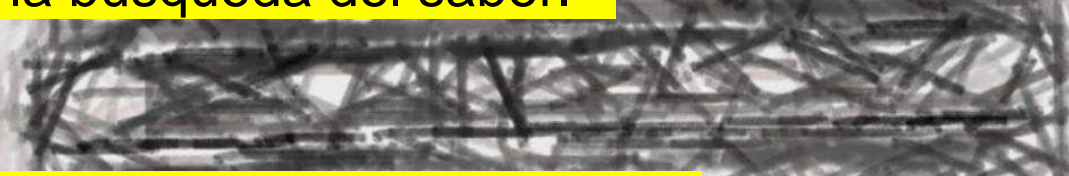

El librote tan pesado me asfixia;

dudo que les moleste a mis coetáneos.

La vida del monje, regalo de Dios,

no me conviene bien, ya no me gusta.

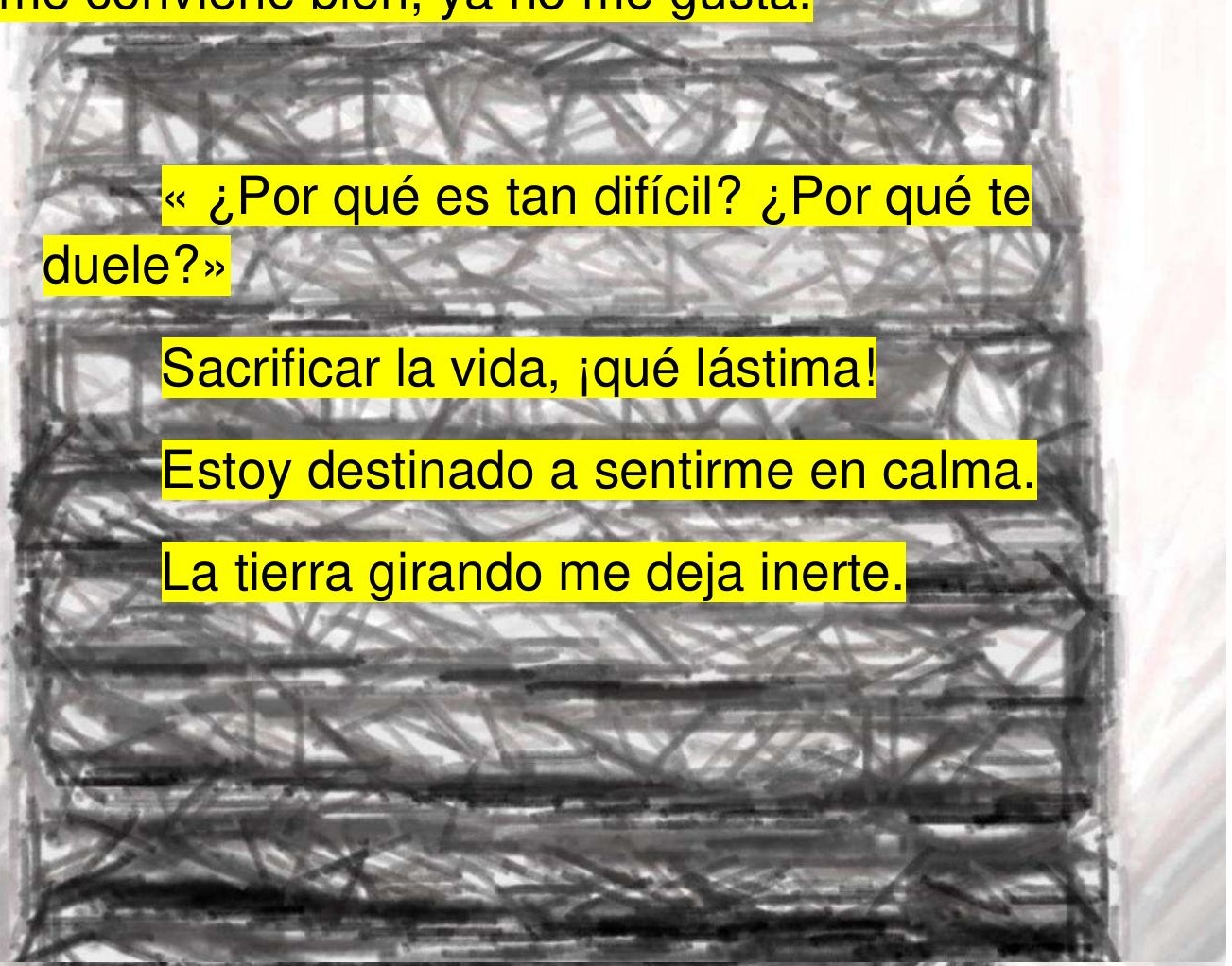

